\title{
Effects of various levels of organic acids and of virginiamycin on performance, blood parameters, immunoglobulins and microbial population of broiler chicks
}

\author{
K. Ghazvinian ${ }^{1 \#}$, A. Seidavi ${ }^{2}$, V. Laudadio ${ }^{3}$, M. Ragni $^{4}$ \& V. Tufarelli ${ }^{3 \#}$ \\ ${ }^{1}$ Faculty of Veterinary Medicine, Semnan University, Semnan, Iran \\ ${ }^{2}$ Department of Animal Science, Rasht Branch, Islamic Azad University, Rasht, Iran \\ ${ }^{3}$ Section of Veterinary Science and Animal Production, Department of DETO, University of Bari 'Aldo Moro', \\ Valenzano, Italy \\ ${ }^{4}$ Department of Agricultural and Environmental Science, University of Bari 'Aldo Moro', Bari, Italy
}

(Received 6 March 2018; Accepted 23 July 2018; First published online 20 November 2018)

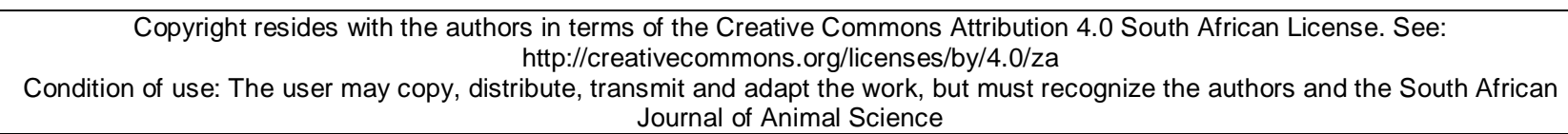

\begin{abstract}
This experiment was conducted to investigate the effects of various levels of organic acids and virginiamycin on performance, blood parameters, immunoglobulin and microbial population of broiler chickens. This trial was conducted in a completely randomized design using five treatments and four replicates. The dietary treatments included a control diet without additives, diets containing $0.05 \%, 0.10 \%$ and $0.15 \%$ mixtures of organic acids, and a diet containing virginiamycin as an antibiotic. Based on the results, there was no significant effect of the experimental diets on feed intake of the broilers during the starter period. However, at the end of the grower period and throughout the rearing period, feed intake was significantly improved by experimental dietary treatments. Moreover, diets including organic acids enhanced the microbial population of broiler gut. Thus, the current findings support the conclusion that organic acids improve productive traits and health status in broiler chickens.
\end{abstract}

Keywords: Broiler, growth, haematology, gut

\#Corresponding author: khghazvinian@semnan.ac.ir; vincenzo.tufarelli@uniba.it

\section{Introduction}

Recent modern poultry farming practices have led to a search for a better production management system. In the past, antibiotics were used to prevent disease and improve the performance of poultry (Okoro et al., 2016; Mahanta et al., 2017). However, the overuse of antibiotics caused concern about increasing bacterial resistance (Alhidary et al., 2016; Khan et al., 2016a). In addition, the ban on antibiotics in Europe increased the urgency to find suitable alternatives to antibiotics (Khan et al., 2012). For this reason, the use of probiotics as a viable alternative to antibiotics to improve the performance and health of broilers received increasing interest (Kabir, 2009; Apata, 2008; Khan \& Naz, 2013; Jahromi et al., 2016). Probiotics possess the capacity to modify the metabolism of poultry by activating enzymes that act to reduce bacteria and ammonia and increase the digestibility of feed, thus creating natural microflora by competitive removal (Khan et al., 2016b). After the birds hatch, microorganisms in the gastro-intestinal tract begin to settle and become endemic. The composition of intestinal microflora can be influenced by many factors, such as age, diet, environment, stress condition and drugs (Rezaei et al., 2015). Specific organic acids reduce the pH of poultry feed and lead to the buffering capacity of feed to control intestinal microbial population (Dhama et al., 2014; Abudabos et al., 2017). Organic acids are among alternative growth promoters that have been used in practice for decades, that have been shown to stimulate growth performance in poultry (Abudabos \& Al-Mufarrej, 2014; Sultan et al., 2015), and that provide better intestinal health for birds to obtain maximum absorption of nutrients (Hayat et al., 2014).

Therefore, this experiment was conducted to investigate the effects of various levels of a mixture of organic acids and of virginiamycin on the performance, blood parameters, immunoglobulins, and microbial population of broiler chickens. 


\section{Materials and Methods}

This research was conducted in a completely randomized design with five treatments and four replications of each treatment. A total of 200 day-old male Ross 308 broiler chicks were used (10 birds $\times$ 5 treatments $\times 4$ replicates). A balanced diet was produced based on software (UFFDA) designed by the University of Georgia, Athens GA, USA. The rations were formulated based on NRC (1994) recommendations and met or exceeded the Ross 308 catalogue indications (Table 1). Throughout the trial, feed and water were offered ad libitum. The dietary treatments included a control diet (Treatment 1 ) without additives and Treatments 2,3 and 4 , which contained $0.05 \%, 0.10 \%$ and $0.15 \%$ organic acid mixture, respectively. The organic acids used in this experiment included lactic acid, formic acid and propionic acid. In an additional treatment (Treatment 5), the antibiotic virginiamycin was added to the diet based on the manufacturer's recommendations. Experimental variables such as feed intake, bodyweight gain and feed conversion ratio (FCR) were measured weekly.

Table 1 Ingredients and nutrient analysis of diets used during the starter and finisher rearing periods

\begin{tabular}{|c|c|c|}
\hline Ingredient (\%) & Starter period (1-21 days old) & Finisher period (22-42 days old) \\
\hline Corn & 44.29 & 47.95 \\
\hline Soybean meal & 34.85 & 26.99 \\
\hline Wheat & 10.00 & 10.0 \\
\hline Meat meal & 5.00 & 5.00 \\
\hline Sunflower oil & 2.17 & 6.25 \\
\hline DCP & 0.78 & 0.54 \\
\hline $\mathrm{CaCO}_{3}$ & 0.86 & 1.05 \\
\hline Sodium bicarbonate & 0.12 & 0.12 \\
\hline $\mathrm{NaCl}$ & 0.25 & 0.25 \\
\hline DL-Methionine & 0.07 & 0.22 \\
\hline Enzyme & 1.00 & 1.00 \\
\hline Antioxidant & 0.02 & 0.02 \\
\hline Vitamin mixture $^{1}$ & 0.25 & 0.25 \\
\hline Mineral mixture ${ }^{2}$ & 0.25 & 0.25 \\
\hline \multicolumn{3}{|l|}{ Chemical analysis } \\
\hline $\mathrm{ME}(\mathrm{kcal} / \mathrm{kg})$ & 2,900 & 3,200 \\
\hline Crude protein (\%) & 22.0 & 19.0 \\
\hline Calcium (\%) & 1.00 & 1.00 \\
\hline Available phosphorus (\%) & 0.48 & 0.42 \\
\hline Lysine (\%) & 1.28 & 1.06 \\
\hline Methionine (\%) & 0.40 & 0.48 \\
\hline Methionine + cysteine (\%) & 0.73 & 0.76 \\
\hline Threonine (\%) & 0.84 & 0.71 \\
\hline
\end{tabular}

${ }_{1}^{1}$ vitamin $A: 5000 \mathrm{IU} / \mathrm{g}$; vitamin $\mathrm{D}_{3}: 500 \mathrm{IU} / \mathrm{g}$; vitamin $\mathrm{E}: 3 \mathrm{mg} / \mathrm{g}$; vitamin $\mathrm{K}_{3}: 1.5 \mathrm{mg} / \mathrm{g}$; vitamin $\mathrm{B}_{2}: 1 \mathrm{mg} / \mathrm{g}$

${ }^{2}$ calcium pantothenate: $4 \mathrm{mg} / \mathrm{g}$; niacin: $15 \mathrm{mg} / \mathrm{g}$; vitamin $\mathrm{B}_{6}$ : $13 \mathrm{mg} / \mathrm{g} ; \mathrm{Cu}: 3 \mathrm{mg} / \mathrm{g} ; \mathrm{Zn}: 15 \mathrm{mg} / \mathrm{g} ; \mathrm{Mn}: 20 \mathrm{mg} / \mathrm{g}$; Fe: 10 $\mathrm{mg} / \mathrm{g} ; \mathrm{K}: 0.3 \mathrm{mg} / \mathrm{g}$

ME: metabolisable energy

At the end of the experimental period, the birds were weighed. The birds with the smallest difference in relative weight to replicate were selected and slaughtered. Carcass yield, breast weight, thigh weight, the percentage of total body weight, gastrointestinal tract and the colon length were measured. To determine the blood parameters, three birds per pen were randomly selected, and $2 \mathrm{~mL}$ blood samples were taken from the wing vein. The serum was immediately separated by centrifugation at $1000 \mathrm{~g}$-force for 10 min. High density lipoprotein (HDL), low density lipoprotein (LDL), triglycerides and total cholesterol serum parameters were 
determined using commercial kits. Birds with a weight closest to the replicate average were sacrificed. The colon was removed and its contents were streaked on agar plates for culture. The total immunoglobulin $\mathrm{M}$ ( $\lg M)$ and $Y(\lg Y)$ titers were determined as described by Dix \& Taylor (1996). To determine bacterial growth and colony counts, the agar collecting tubes were weighed, wrapped in an aluminium sheet, and autoclaved for $10 \mathrm{~min}$. The culture media were prepared 24 hours before the samples were poured into petri dishes. Man-Rogosa-Sharpe agar was used to grow Lactobacilli, and eosin methylene blue to grow Escherichia coli. Samples were transferred at the laboratory in the tubes and weighed again. The amount of sample in each tube was calculated from the difference between these two values. Tubes were shaken for $\sim 30$ minutes to isolate bacteria from the gastrointestinal contents and to prepare the suspension. A total of $1 \mathrm{~mL}$ was removed from the suspension and added to $9 \mathrm{~mL}$ phosphate-buffered saline (PBS) in another tube. The suspension was prepared from $10^{-1}$ dilutions, and serial dilutions were done $\left(10^{-2}, 10^{-3}, 10^{-4}, 10^{-5}\right.$ and $\left.10^{-6}\right)$. Then, $100 \mu \mathrm{L}$ was removed from dilutions $\left(10^{-4}, 10^{-5}\right.$, and $\left.10^{-6}\right)$ and poured into the petri dish with the medium, and distributed completely to all parts of the medium. Lactobacilli were incubated at $37^{\circ} \mathrm{C}$ in anaerobic conditions for 72 hours. An anaerobic jar was used to create anaerobic conditions. Bacteria in the petri dishes were counted with a colony counter. Bacterial counts were reported as logarithm number of bacteria per gram sample.

Data were analysed by analysis of variance using a one-way procedure based on a completely randomized design. Data were analysed by $S S^{\circledR} 8.0$ statistical software (SAS, 2000, Institute Inc., Cary, NC, USA) and the GLM procedure was used. The means ( \pm SEM) were compared with Duncan's test. Results were considered significantly different at $P<0.05$.

\section{Results}

The effects of the experimental diets on the feed intake of broilers during the starter period were not significant $(P>0.05)$ (data not shown). However, the feed intake over the entire period was significant $(P<0.05)$. Treatment 5 had the highest rate of feed intake, and the control the lowest (Table 2).

Table 2 Effects of experimental diets on cumulative feed intake, bodyweight gain and feed efficiency of broilers

\begin{tabular}{lccc}
\hline Item & Cumulative feed intake $(\mathbf{k g})$ & Body weight gain (kg/bird) & Feed efficiency (g/g) \\
\hline Control & $3.440^{\mathrm{c}}$ & $1.890^{\mathrm{d}}$ & $1.82^{\mathrm{a}}$ \\
Organic acids & & & $1.82^{\mathrm{a}}$ \\
$0.05 \%$ & $3.528^{\mathrm{c}}$ & $1.939^{\mathrm{cd}}$ & $1.81^{\mathrm{a}}$ \\
$0.10 \%$ & $3.581^{\mathrm{b}}$ & $1.976^{\mathrm{c}}$ & $1.69^{\mathrm{b}}$ \\
$0.15 \%$ & $3.547^{\mathrm{b}}$ & $2.098^{\mathrm{b}}$ & $1.67^{\mathrm{b}}$ \\
Virginiamycin & $3.670^{\mathrm{a}}$ & $2.197^{\mathrm{a}}$ & 0.0772 \\
SEM & 0.1312 & 0.1004 & 0.001 \\
P-value & 0.018 & 0.001 &
\end{tabular}

a-d: Different superscripts within the same column indicate significant differences among treatment groups

The results showed that treatments 4 and 5 had the greatest increase in bodyweight gain compared with the other groups $(P<0.05$; Table 2$)$. According to these results, the best feed efficiency was detected for diets 4 and $5(P<0.05)$, and the lower feed conversion ratio (FCR) was observed for control treatment and the remaining diets (Table 2 ).

The data analysis showed that FCR was related to the group receiving the diet containing Treatment 5 $(P<0.05)$ in the caecal and intestinal tract weight, while Treatment 3 showed the smallest increases $(P$ $<0.05)$ (Table 3). No differences were detected in broiler carcass, breast and thigh yields. 
Table 3 Effect of experimental diets on carcass characteristics (\%) of broilers

\begin{tabular}{|c|c|c|c|c|}
\hline Item & Carcass yield \% & Breast yield \% & Thigh yield \% & Digestive tract \% \\
\hline Control & 60.1 & 34.8 & $30.4^{\mathrm{bc}}$ & $7.9^{c}$ \\
\hline \multicolumn{5}{|l|}{ Organic acids } \\
\hline $0.05 \%$ & 60.8 & 35.2 & $29.7^{c}$ & $8.5^{b c}$ \\
\hline $0.10 \%$ & 61.2 & 35.4 & $30.8^{\mathrm{abc}}$ & $8.6^{b}$ \\
\hline $0.15 \%$ & 62.8 & 36.1 & $31.6^{\mathrm{ab}}$ & $10.2^{\mathrm{a}}$ \\
\hline Virginiamycin & 61.9 & 36.5 & $32.3^{\mathrm{a}}$ & $8.2^{\mathrm{bc}}$ \\
\hline SEM & 2.33 & 0.23 & 0.25 & 0.07 \\
\hline$P$-value & 0.613 & 0.212 & 0.038 & 0.001 \\
\hline
\end{tabular}

${ }^{\mathrm{a}-\mathrm{c}}$ : Different letters within the same column indicate significant differences among treatment groups $(P<0.05)$

The results show that the HDL levels among the groups were not significant $(P<0.05)$, with Treatments 3 and 4 showing the maximum concentration of HDL compared with the other treatments (Table 4). The control diet and Treatment 3 had the highest and lowest blood levels of LDL, respectively Treatments 2, 3 and 4 had similar blood cholesterol levels $(P>0.05)$. Those with the lowest cholesterol were fed Treatment 4, while those with the greatest amount of cholesterol were fed the control diet and Treatment 5.

Table 4 Effects of the experimental diets on blood parameters (mg/dL) of broilers

\begin{tabular}{lcccc}
\hline Item & HDL & LDL & Total cholesterol & Triglycerides \\
\hline Control & $71.1^{\mathrm{c}}$ & $52.1^{\mathrm{a}}$ & $143.3^{\mathrm{a}}$ & $149.4^{\mathrm{c}}$ \\
Organic acids & & & \\
$\quad 0.05 \%$ & $66.1^{\mathrm{d}}$ & $44.4^{\mathrm{b}}$ & $130.8^{\mathrm{b}}$ & $140.8^{\mathrm{ab}}$ \\
$0.10 \%$ & $91.5^{\mathrm{a}}$ & $35.2^{\mathrm{c}}$ & $133.5^{\mathrm{b}}$ & $126.1^{\mathrm{bc}}$ \\
$0.15 \%$ & $89.4^{\mathrm{a}}$ & $38.9^{\mathrm{bc}}$ & $121.5^{\mathrm{c}}$ & $118.8^{\mathrm{d}}$ \\
Virginiamycin & $77.1^{\mathrm{b}}$ & $34.4^{\mathrm{b}}$ & $134.5^{\mathrm{ab}}$ & $132.8^{\mathrm{bc}}$ \\
SEM & 0.64 & 0.81 & 1.38 & 1.32 \\
P-value & 0.001 & 0.001 & 0.003 & 0.001 \\
\hline
\end{tabular}

a-d: Different letters within the same column indicate significant differences among treatment groups

HDL: high density lipoprotein; LDL: Iow density lipoprotein

The results for immunoglobulin $Y$ and $M$ levels before vaccination, and with a diet containing a mixture of organic acids, showed a significant $(P<0.05)$ increase in IgY and M compared with Treatments 2, 3 and 4. The measurements after immune challenge suggest that diets that contained blends of organic acids yielded the greatest increase in immunoglobulin levels among the groups $(P<0.05)$, while the control and Treatment 5 had the lowest levels of both immunoglobulins (Table 5).

There were significant differences in $E$. coli population between the control and experimental diets $(P<0.05)$. The minimum number of $E$. coli population was obtained in broilers fed Treatment 5 and Treatments 2 and 3, whereas the chicks in control diet had the highest E. coli count. The Lactobacillus population for chicks fed a mixture of organic acids (Treatments 2, 3 and 4) was significantly increased compared with the other diets (control and Treatment 5) $(P<0.05)$ (Table 6).

The greatest number of Lactobacillus was observed in the ileum content from broilers fed the mixture of organic acids in the diet containing $0.15 \%(P<0.05)$, while the lowest number of Lactobacillus was found in the ileum of broilers fed Treatment 5. 
Table 5 Effect of the experimental diets on immune system response in broilers

\begin{tabular}{|c|c|c|c|c|}
\hline Item & $\lg Y$ (before) & IgM (before) & IgY (after) & IgM (after) \\
\hline Control & $320.5^{\mathrm{b}}$ & $117.3^{\mathrm{c}}$ & $427.5^{c}$ & $136.2^{c}$ \\
\hline \multicolumn{5}{|l|}{ Organic acids } \\
\hline $0.05 \%$ & $329^{a b}$ & $134^{\mathrm{ab}}$ & $481.5^{\mathrm{a}}$ & $144.8^{b c}$ \\
\hline $0.10 \%$ & $341^{\mathrm{ab}}$ & $134^{\mathrm{ab}}$ & $464.7^{\mathrm{b}}$ & $148.5^{\mathrm{ab}}$ \\
\hline $0.15 \%$ & $341^{\mathrm{ab}}$ & $142.3^{\mathrm{a}}$ & $480^{\mathrm{ab}}$ & $156.5^{\mathrm{a}}$ \\
\hline Virginiamycin & $371.3^{\mathrm{a}}$ & $125.3^{b c}$ & $427.7^{c}$ & $138.2^{\mathrm{bc}}$ \\
\hline SEM & 2.24 & 1.56 & 2.32 & 1.51 \\
\hline$P$-value & 0.005 & 0.001 & 0.002 & 0.033 \\
\hline
\end{tabular}

a-c: Different letters within the same column indicate significant differences among treatment groups.

IgY: immunoglobulin Y; IgM: immunoglobulin M

Table 6 The effects of the experimental treatments on broiler microbial population (CFU/g)

\begin{tabular}{lcc}
\hline Item & Escherichia coli & Lactobacillus \\
\hline Control & $79.5^{\mathrm{a}}$ & $62.7^{\mathrm{c}}$ \\
Organic acids & & \\
$0.05 \%$ & $42.5^{\mathrm{b}}$ & $93.7^{\mathrm{b}}$ \\
$0.10 \%$ & $31.1^{\mathrm{c}}$ & $109.3^{\mathrm{a}}$ \\
$0.15 \%$ & $24.2^{\mathrm{c}}$ & $109.7^{\mathrm{a}}$ \\
Virginiamycin & $19.7^{\mathrm{c}}$ & $75.3^{\mathrm{c}}$ \\
SEM & 1.61 & 1.93 \\
P-value & 0.01 & 0.01
\end{tabular}

${ }^{a-c}$ : Different letters within the same column indicate significant differences among treatment groups

\section{Discussion}

The findings of this study showed that supplementing broiler diet with organic acids had little effect on performance. They also suggest that this could be caused by microbial flora such as Lactobacillus. These findings are consistent with those of Kermanshahi \& Rostami (2006). However, the current results are in opposition to those of Khaksefidi \& Rahimi (2004) and Taherpour et al. (2009). The increase in Lactobacillus bacteria with Treatments 2, 3 and 4 suggested a beneficial effect on the overall bacterial flora. Organic acids have the best chance of increasing the microbial population of beneficial bacteria. The current findings were consistent with those of Mohan et al. (1996), Kabir et al. (2004), Khaksefidi \& Rahimi (2004) and Kermanshahi \& Rostami (2006) in broilers.

In the current trial, a significant difference in FCR was observed in Treatments 4 and 5, suggesting that the addition of organic acids may support nutrient digestibility and bioavailability. It is possible that organic acids act by reducing the acidity of the digestive system, leading to better utilization of nutrients.

These results are consistent with those of Vicente et al. (2007), but disagree with those of Khaksefidi \& Rahimi (2004). It appears that the organic acids used in this experiment affected the metabolism of nutrients. It is likely that organic acids tested here have the effect of increasing the size and morphology of the digestive system. Epithelial cells of the gastrointestinal tract could cause weight gain. Organic acids may also determine an increase in intestinal villi and microvilli, and increase the weight of the caecum and colon (Rehman et al., 2009; Iqbal et al., 2018).

Serum HDL levels among groups were significant, with the highest values being observed in diets containing the mixture of organic acids (at 0.10 and $0.15 \%$ ). These findings were consistent with the results of studies by Haghighi et al. (2005), but inconsistent with those of Panda (2000) and Taherpour et al. (2009), in which probiotics, prebiotics and organic acids resulted in significantly reduced serum LDL in broilers at 42 
days. In the present experiment, the lowest blood levels of LDL were obtained in birds fed a diet containing the mixture of organic acids at $0.1 \%$.

Accordingly, feeding organic acids showed lower total cholesterol levels compared with the control diet. This result is consistent with those of Mohan et al. (1996) and Hossain et al. (2008). It seems that the reduction of blood cholesterol was because of its direct use by bacteria that produce lactic acid and conjugated bile acids. Organic acids may increase the faecal excretion of amino acids and cholesterol absorption from the intestine. Furthermore, the highest triglyceride levels were found in the control diet, while Treatment 4 showed significantly lower triglycerides. Taherpour et al. (2009) did not find a dietary effect on triglycerides. However, the current findings agree with those of Gibson \& Fuller (2000) and Kalavaty et al. (2003). The highest immunoglobulin titers were found in the diet containing $0.15 \%$ of organic acid mixture. This result is consistent with the findings of Kabir et al. (2004) and Haghighi et al. (2005).

Increasing the population of beneficial intestinal bacteria led to the hypothesis that the competitive removals of pathogenic bacteria from the intestines are removed (Rantala \& Nurmi, 1973). The current results showed that organic acids caused a significant reduction of the pathogen population, since $E$. coli declined in Treatments 2, 3 and 4 compared with control. A significant decrease in the population of Lactobacillus was observed using antibiotic supplementation. Adding organic acids led to an increasing amount of lactic acid in the digestive tract, and to a reduction of pathogenic bacteria such as $E$. coli, which can prevent lactic acid producing bacteria, such as Lactobacillus $\mathrm{sp}$. The results of this study are consistent with those of Patterson \& Burkholder (2003), Kim et al. (2003) and Kermanshahi \& Rostami (2006).

\section{Conclusion}

Based on the current findings, as an alternative to antibiotics, organic acids support broiler production by modulating harmful bacterial species, increasing beneficial bacterial species and maintaining the growth and health parameters of poultry.

\section{Acknowledgments}

The authors would like to thank the manager of Urmia Youvalar Layer Farm, Mr. Jamshid Azimi, for financial support of this study.

\section{Authors' Contributions}

All the authors contributed equally and commented on the early and final versions of the manuscript.

\section{Conflict of Interest Declaration}

The authors have no conflict of interest to declare.

\section{References}

Abudabos, A.M. \& Al-Mufarrej, S.I., 2014. Effects of organic acid supplementation on antioxidant capacity and immune responses of broilers challenged orally with Salmonella enterica subsp. enterica Typhimurium. S. Afr. J. Anim. Sci. 44, 360-370.

Abudabos, A.M., Alyemni, A.H., Dafalla, Y.M. \& Khan, R.U., 2017. Effect of organic acid blend and Bacillus subtilis alone or in combination on growth traits, blood biochemical and antioxidant status in broilers exposed to Salmonella typhimurium challenge during the starter phase. J. Appl. Anim. Res. 45, 538-542.

Alhidary, I.A., Abdelrahman, M.M. \& Khan R.U., 2016. Comparative effects of direct-fed microbial alone or with a traces mineral supplement on the productive performance, blood metabolites and antioxidant status of grazing Awassi lambs. Env. Sci. Pollut. Res. 23, 25218-25223.

Apata, D.F., 2008. Growth performance, nutrient digestibility and immune response of broiler chicks fed diets supplemented with a culture of Lactobacillus bulgaricus. J. Sci. Food Agric. 88, 1253-1258.

Dhama, K., Tiwari, R., Khan, R.U., Chakroborty, S., Gopi, M., Kathik, K., Saminathan, M., Desingu, P.A. \& Sunkara, L.T., 2014. Growth promoters and novel feed additives improving poultry production and health, bioactive principles and beneficial applications: the trends and advances - a review. Int. J. Pharmacol. 10, 129-159.

Dix, M.C. \& Taylor, R.L., 1996. Differential antibody responses in 6.B major histocompatibility (B) complex congenic chickens. Poult. Sci. 75, 203-207.

Gibson, G.R. \& Fuller, R., 2000. Aspects of in vitro and in vivo research approaches directed toward identifying probiotics and probiotics for human use. J. Nutr. 130, 391-395.

Haghighi, H.R., Gong, J., Gyles, C.L., Hayes, M.A., Sanei, B., Parvizi, P., Gisavi, H., Chambers, J.R. \& Sharif, S., 2005. Modulation of antibody-mediated immune response by probiotics in chickens. Clin. Diagn. Lab. Immunol. 12, 1387-1392.

Hayat, T.A. Sultan, R.U. Khan, S. Khan, Z., Ullah, R. \& Aziz, T., 2014. Impact of organic acid on some liver and kidney function tests in Japanese quails, Coturnix coturnix japonica. Pak. J. Zool. 46(4), 1179-1182.

Iqbal, Z., Roberts, J., Perez-Maldonado, R.A., Goodarzi Boroojeni, F., Swick, R.A. \& Ruhnke, I., 2018. Pasture, multienzymes, benzoic acid and essential oils positively influence performance, intestinal organ weight and egg quality in free-range laying hens. Br. Poult. Sci. 59, 180-189. 
Jahromi, M.F., Altaher, Y.W., Shokryazdan, P., Ebrahimi, R., Ebrahimi, M., Idrus, Z., Goh, Y.M., Tufarelli, V. \& Liang, J.B., 2016. Dietary supplementation of a mixture of lactobacillus strains enhances performance of broiler chickens raised under heat stress conditions. Int. J. Biometeorol. 60, 1099-1110.

Kabir, S., Rahman, M.M., Rahman, M.B. \& Ahmad, S.U., 2004. The dynamics of probiotics on growth performance and immune response in broiler. J. Poult. Sci. 3, 61-64.

Kabir, S.M., 2009. The role of probiotics in the poultry industry. Int. J. Mol. Sci. 10, 3531-3546.

Kalavathy, R., Abdullah, N., Jalaludin, S. \& Ho, Y.W., 2003. Effect of Lactobacillus cultures on growth performance, abdominal fat deposition, serum lipids and weight of organs of broiler chickens. Br. Poult. Sci. 44, 139-144.

Kermanshahi, H. \& Rostami, H., 2006. Influence of supplemental dried whey on broiler performance and cecal flora. Int. J. Poult. Sci. 5, 538-543.

Khaksefidi, A. \& Rahimi, S., 2004. Evaluation of the effect various levels of probiotic on blood factors, performance and carcass characteristics of broiler chicks under acute heat stress. J. Agric. Sci. Technol. 18, 149-158.

Khan, R.U. \& Naz, S., 2013. The applications of probiotics in poultry production. Wrld Poult. Sci. J. 69, 621-632.

Khan, R.U., Naz, S., Nikousefat, Z., Tufarelli, V., Javdani, M., Qureshi, M.S. \& Laudadio, V., 2012. Potential applications of ginger (Zingiber officinale) in poultry diets. World Poult. Sci. J. 68, 245-252.

Khan, R.U., Chand, N. \& Ali, A., 2016a. Effect of organic acids on the performance of Japanese quails. Pakistan J. Zool. 48, 1799-1803.

Khan, R.U., Naz, S., Dhama, K., Kathrik, K., Tiwari, R., Abdelrahman, M.M., Alhidary, I.A. \& Zahoor, A., 2016b. Directfed microbial: Beneficial applications, modes of action and prospects as a safe tool for enhancing ruminant production and safeguarding health. Int. J. Pharmacol. 12, 220-231.

Kim, S.H., Park, S.Y., Yu, D.J., Lee, S.J., Ryu, K.S. \& Lee, D.G., 2003. Effects of feeding Aspergillus oryzae ferments on performance, intestinal microflora, blood serum components and environmental factors in broilers. Korean J. Poult. Sci. 30, 151-159.

Mahanta, J.D., Borgohain, B., Sharma, M., Sapcota, D. \& Hussain, J., 2017. Effect of dietary supplementation of herbal growth promoter on performance of commercial broiler chickens. Ind. J. Anim. Res. 51, 1097-1100.

Mohan, B., Kadirvel, R., Nataragen, A. \& Bhaskaran, M., 1996. Effect of probiotic supplementation on growth, nitrogen utilization and serum cholesterol in broilers. J. Poult. Sci. 37, 395-401.

NRC (National Research Council), 1994. Nutrient Requirements for Poultry. 9th revised edition. National Academy Press, Washington, DC.

Okoro, V.M.O., Nwokeocha, A.C.C., Ijezie, C.O., Mbajiorgu, C.A. \& Mbajiorgu, E.F., 2016. Effect of varying dietary supplemental inclusion levels of onion and garlic on semen quality characteristics of Hubbard white breeder broiler cocks aged 35-41 weeks old. Ind. J. Anim. Res. 50, 922-929.

Panda, A.K., Reddy, M.R., Rao, S.V.R., Raju, M.V.L.N. \& Praharaj, N.K., 2000. Growth, carcass characteristics, immunocompetence and response to Escherichia coli of broilers fed diets with various levels of probiotic. Archiv. Geflugelkd. 64, 152-156.

Patterson, J.A. \& Burkholder, K.M., 2003. Application of prebiotic and probiotic in poultry production. Poult. Sci. 82, 627-631.

Rantala, M. \& Nurmi, E., 1973. Prevention of the growth of Salmonella infantis in chicks by the flora of the alimentary tract of chickens. Br. Poult. Sci. 14, 627-630.

Rehman, H., Vahjen, W., Kohl-Parisini, A., ljaz, A. \& Zentek, J., 2009. Influence of fermentable carbohydrates on the intestinal bacteria and enteropathogens in broilers. Wrld Poult. Sci. J. 65, 75-90.

Rezaei, S., Faseleh Jahromi, M., Liang, J.B., Zulkifli, I., Farjam, A.S., Laudadio, V. \& Tufarelli, V., 2015. Effect of oligosaccharides extract from palm kernel expeller on growth performance, gut microbiota and immune response in broiler chickens. Poult. Sci., 94: 2414-2420.

SAS, 2000. SAS User's guide: Statistics. SAS Institute, Inc., Cary, N.C., USA.

Shariatmadari, F. \& Forbes, J.M., 2005. Performance of broiler chickens had given whey in the food and/or drinking water. Br. Poult. Sci., 46, 498-505.

Sultan, A., Ullah, T., Khan, S. \& Khan, R.U., 2015. Effect of organic acid supplementation on the performance and ileal microflora of broiler during finishing period. Pak. J. Zool. 47, 635-639.

Taherpour, K., Moravej, H., Shivazad, M., Adibmoradi, M. \& Yakhchali, B., 2009. Effects of dietary probiotic, probiotic and butyric acid glycerides on performance and serum composition in broiler chickens. Afr. J. Biotechnol. 8, 3229-3234.

Vicente, J.L., Aviña, L., Torres-Rodriguez, A., Hargis, B. \& Tellez, G., 2007. Effect of a Lactobacillus spp-based probiotic culture product on broiler chicks' performance under commercial conditions. Int. J. Poult. Sci. 6, 154-156. 